\title{
Synthesis and In Vitro Cytotoxic Activity of Chromenopyridones
}

\author{
Balwinder Singh, ${ }^{1}$ Vishal Sharma, ${ }^{1}$ Gagandeep Singh, ${ }^{1}$ Rakesh Kumar, ${ }^{2}$ \\ Saroj Arora, ${ }^{2}$ and Mohan Paul Singh Ishar ${ }^{1}$ \\ ${ }^{1}$ Bio-Organic and Photochemistry Laboratory, Department of Pharmaceutical Sciences, Guru Nanak Dev University, \\ Amritsar 143005, India \\ ${ }^{2}$ Botanical and Environmental Sciences, Guru Nanak Dev University, Amritsar 143005, India
}

Correspondence should be addressed to Mohan Paul Singh Ishar; mpsishar@yahoo.com

Received 19 October 2012; Revised 27 November 2012; Accepted 11 December 2012

Academic Editor: Giulio Rastelli

Copyright ( 2013 Balwinder Singh et al. This is an open access article distributed under the Creative Commons Attribution License, which permits unrestricted use, distribution, and reproduction in any medium, provided the original work is properly cited.

Novel substituted chromenopyridones $(\mathbf{3 a}-\mathbf{j}$ and $\mathbf{6 a}-\mathbf{d})$ were synthesized and evaluated in vitro for the cytotoxic activity against various human cancer cell lines such as prostate (PC-3), breast (MCF-7), CNS (IMR-32), cervix (Hela), and liver (Hep-G2). preliminary cytotoxic screening showed that all the compounds possess a good to moderate inhibitory activity against various cancer cell lines. Particularly, compound $\mathbf{6 b}$ bearing allyl moiety displayed a significant cytotoxic potential in comparison to standard drugs.

\section{Introduction}

Cancer is the most dreaded group of diseases in which abnormal cells divide aggressively without control invade and spread to other parts of the body through the blood and lymph systems [1]. Despite tremendous advancements both in early diagnosis and approaches to treatment, cancer still remains an unconquered problem [1]. The development of new chemotherapeutic agents for the treatment of cancer with fewer side effects is an important goal for medicinal chemists. Heterocyclic compounds display a high degree of structural diversity and constitute the largest, most varied family of organic compounds evaluated for anticancer potential in past decades [2]. A perusal of the literature revealed that chromone framework constitutes an integral part of several natural products and biologically active molecules. Chromone derivatives exhibit a remarkable spectrum of pharmacological activities including antitumor [3], anti-inflammatory [4], antibacterial [5], antifungal [6], antioxidant [7], anti-HIV [8], vasodilator [9], antiviral [10], and antiallergenic [11]. Naturally occurring chromone based molecule, morusin, isolated from a Chinese herb, has been reported to be a potent antitumor agent [12]. Recently, we have developed some chromone based compounds such as substituted 3-(5-phenyl-3H-[1,2,4]dithiazol-3-yl)chromen4-one and substituted 4-oxo-4H-chromene-3-carbothioic acid $N$-phenylthioamide, which display a promising cytotoxic activity against a number of human cancer cell lines [13]. Derivatives of 6-chloro-/fluorochromone have also been reported as potential topoisomerase inhibitor anticancer agents [14].

2-Pyridone moiety is another substructural unit of several natural and synthetic molecules exhibiting diverse biological activities such as antitumor [15, 16], antimicrobial [17], antiinflammatory [18], antiviral [19], and so forth. For instance, camptothecin, isolated from Camptotheca acuminate [20], is a naturally occurring DNA topoisomerase I poison possessing a pyridone nucleus. Due to a remarkable antiproliferative activity of camptothecin, various synthetic derivatives have been synthesized and among them, two water-soluble derivatives have gained FDA approval, that is, irinotecan to treat colorectal cancers and topotecan for ovarian and smallcell lung cancers [21]. Additionally, some camptothecinoids such as lurtotecan and exatecan are currently under clinical trials [22]. Keeping in view the high anticancer activity of both chromone and pyridones, it was decided to synthesize chromenopyridones and evaluate their cytotoxic potential against various human cancer cell lines. 


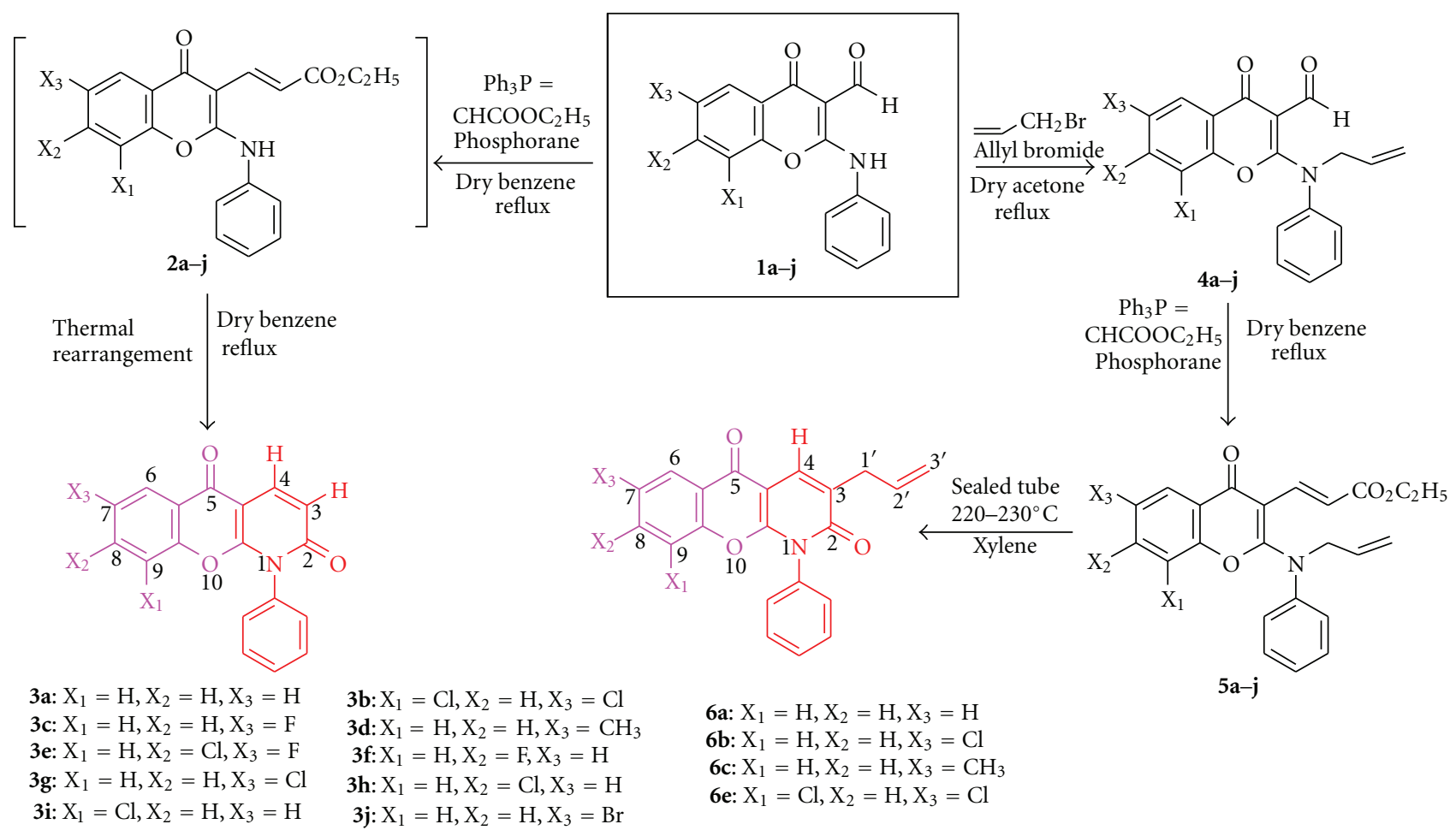

Scheme 1: Synthesis of chromenopyridones $\mathbf{3 a - j}$ and $\mathbf{6 a - d .}$

\section{Result and Discussion}

Variously substituted 2-anilino-3-formylchromones (1a-j) were reacted with ethoxycarbonylmethylene-triphenylphosphorane in dry benzene leading to the formation of intermediates $(\mathbf{2} \mathbf{a}-\mathbf{j})$, which rearranged thermally on refluxing, yielding the corresponding substituted 1-phenyl5-oxo-chromano[2,3-b]-dihydro-2[1H]-pyridones (3a-j); the latter were purified by column chromatography over silica gel (60-120 mesh) using 8\% ethyl acetate in hexane $[23,24]$. All purified compounds were characterized by spectroscopic techniques ( ${ }^{1} \mathrm{H}$ and ${ }^{13} \mathrm{C}$ NMR, IR, mass) and elemental analysis (Scheme 1 and Table 1 ).

${ }^{1} \mathrm{H}$ NMR spectra of compound $\mathbf{3 b}$ showed two olefinic doublets, one at $\delta 8.20$ and another at $\delta 6.90 \mathrm{ppm}$ attributed to $\mathrm{C}_{4}-\mathrm{H}$ and $\mathrm{C}_{3}-\mathrm{H}$, respectively, with coupling constant value $9.0 \mathrm{~Hz} .{ }^{13} \mathrm{C}$ NMR spectrum of $\mathbf{3 b}$ showed resonance at $\delta$ 175.3 and $\delta 164.6 \mathrm{ppm}$ attributed to the $(\mathrm{C}=\mathrm{O})$ group of both chromone and pyridone moiety, respectively, which was further corroborated by IR spectrum which showed strong bands at 1693 and $1687 \mathrm{~cm}^{-1}$. IR spectrum also showed $\mathrm{C}-\mathrm{N}$ stretching at $1419 \mathrm{~cm}^{-1}$ of pyridone ring. The structure $\mathbf{3 b}$ is further confirmed by mass spectrum which revealed a molecular ion peak at $m / z 358\left(\mathrm{M}^{+}\right)$.

Keeping in view the high antitumor potential of isoprenyl/allyl substituted chromone derivatives [12-25], allyl substituted compounds $\mathbf{6 a - d}$ were also synthesized. For the synthesis of latter, substituted 2-anilino-3-formylchromones (1a-d) were reacted with allyl bromide in the presence of fused potassium carbonate to obtain $N$-allylated products (4a-d); the latter on refluxing with ethoxycarbonylmethylene-triphenyl-phosphorane in dry benzene afforded Wittig product that is $2-(N$-allyl $)-3-(E$ - $\beta$-ethoxycarbonyl-ethenyl)-chromones (5a-d). When xylene solutions of $\mathbf{5 a - d}$ were sealed in pyrex glass tubes and heated at $220-230^{\circ} \mathrm{C}$ for 6 hours, these thermally rearranged to substituted 3-allyl-1-phenyl-5-oxo-chromano[2,3-b]dihydro$2[1 H]$-pyridones $(\mathbf{6 a}-\mathbf{d}$, Scheme 1 and Table 1$)$. Compounds 6a-d were purified by column chromatography over silica gel $(60: 120 \mathrm{mesh})$ using hexane and ethyl acetate in the ratio of $9: 1$ and characterized by spectroscopic techniques $\left({ }^{1} \mathrm{H}\right.$ and ${ }^{13} \mathrm{C}$ NMR, IR, mass) and elemental analysis [24].

The ${ }^{1} \mathrm{H}$ NMR spectra of compound $\mathbf{6 b}$ shows the peaks at 6.01-5.93 (m, 1H, C $\left.2^{\prime}-\mathrm{H}\right), 5.22\left(\mathrm{~d}, 1 \mathrm{H}, J=11.4 \mathrm{~Hz}, \mathrm{C}_{3^{\prime}}\right.$ $\mathrm{H}), 5.12\left(\mathrm{~d}, 1 \mathrm{H}, J=8.4 \mathrm{~Hz}, \mathrm{C}_{3^{\prime}}-\mathrm{H}\right)$, and $3.31(\mathrm{~d}, 2 \mathrm{H}, J=$ $6.6 \mathrm{~Hz}, \mathrm{C}_{1^{\prime}}-\mathrm{Hs}$ ) alluding to the presence of allyl moiety. Assigned structure is also supported by the presence of a singlet at $\delta 8.09$ attributed to $\mathrm{C}_{4}-\mathrm{H}$. The presence of $2-$ pyridone moiety in $\mathbf{6 b}$ was established by a band in the IR spectrum around $1643 \mathrm{~cm}^{-1}$ and ${ }^{13} \mathrm{C}$ NMR chemical shift of $\mathrm{C}_{2}$ ( $\delta$ 160.6); overall ${ }^{13} \mathrm{C}$ NMR assignments and mass spectra are in consonance with the assigned structures [24].

The cytotoxic potential of all the synthesized compounds $3 \mathbf{a}-\mathbf{j}$ and $\mathbf{6 a - d}$ was observed against various human cancer cell lines such as prostate (PC-3), breast (MCF-7), CNS (IMR-32), cervix (Hela) and liver (Hep-G2) according to the procedure of Skehan et al. [26]. The growth inhibition (\%) was determined in triplicate at concentrations 10, 30, 50 , and $100 \mu \mathrm{M} / \mathrm{mL}$ by using paclitaxel, 5-fluorouracil and mitomycin- $\mathrm{C}$ as a positive control. $\mathrm{IC}_{50}$ value $(\mu \mathrm{M})$, which is 
TABLE 1: Reaction time and yield (\%) of various compounds $\mathbf{3 a}-\mathbf{j}$ and $\mathbf{6 a}-\mathbf{d}$.

\begin{tabular}{lccccc}
\hline $\begin{array}{l}\text { Compound } \\
\text { number }\end{array}$ & $\mathrm{X}_{1}$ & $\mathrm{X}_{2}$ & $\mathrm{X}_{3}$ & $\begin{array}{c}\text { Reaction } \\
\text { time }(\mathrm{h})\end{array}$ & $\begin{array}{c}\text { Yield (\%) of } \\
\text { products }\end{array}$ \\
\hline 3a & $\mathrm{H}$ & $\mathrm{H}$ & $\mathrm{H}$ & 12 & 90 \\
3b & $\mathrm{Cl}$ & $\mathrm{H}$ & $\mathrm{Cl}$ & 12 & 92 \\
3c & $\mathrm{H}$ & $\mathrm{H}$ & $\mathrm{F}$ & 12 & 92 \\
3d & $\mathrm{H}$ & $\mathrm{H}$ & $\mathrm{CH}_{3}$ & 12 & 95 \\
3e & $\mathrm{H}$ & $\mathrm{Cl}$ & $\mathrm{F}$ & 12 & 89 \\
3f & $\mathrm{H}$ & $\mathrm{F}$ & $\mathrm{H}$ & 12 & 90 \\
3g & $\mathrm{H}$ & $\mathrm{H}$ & $\mathrm{Cl}$ & 12 & 93 \\
3h & $\mathrm{H}$ & $\mathrm{Cl}$ & $\mathrm{H}$ & 12 & 95 \\
3i & $\mathrm{Cl}$ & $\mathrm{H}$ & $\mathrm{H}$ & 12 & 94 \\
3j & $\mathrm{H}$ & $\mathrm{H}$ & $\mathrm{Br}$ & 12 & 95 \\
$\mathbf{6 a}$ & $\mathrm{H}$ & $\mathrm{H}$ & $\mathrm{H}$ & 6 & 96 \\
6b & $\mathrm{H}$ & $\mathrm{H}$ & $\mathrm{Cl}$ & 6 & 94 \\
$\mathbf{6 c}$ & $\mathrm{H}$ & $\mathrm{H}$ & $\mathrm{CH}$ & 6 & 95 \\
$\mathbf{6 d}$ & $\mathrm{Cl}$ & $\mathrm{H}$ & $\mathrm{Cl}$ & 6 & 95 \\
\hline
\end{tabular}

the concentration required to inhibit cancer cell proliferation by $50 \%$ after the exposure of cells to test compounds have also been determined (Table 2). In the case of prostate cancer cell line (PC-3), compound $\mathbf{6 b}$ displayed promising cytotoxicity with $\mathrm{IC}_{50}=2.4$, followed by compounds $6 \mathrm{c}$ and 6d which showed moderate inhibitory potential with $\mathrm{IC}_{50}=$ 13.4 and 14.1, respectively. The compound $\mathbf{6 b}$ and $\mathbf{6 c}$ showed a significant inhibitory activity against breast cancer cell line $(\mathrm{MCF}-7)$ with $\mathrm{IC}_{50}=10.7$ and 11.0 , whereas compounds 6d and $3 \mathbf{h}$ showed good cytotoxicity with $\mathrm{IC}_{50}=14.6$ and 15.5 against the same cell line. In case of CNS cancer cell line (IMR-32), compounds $\mathbf{6 b}$ and $\mathbf{6} \mathbf{d}$ showed maximum inhibition with $\mathrm{IC}_{50}=13.2$ and 16.3. Furthermore, in case of cervix cancer cell line (Hela) and liver cancer cell line (HepG2), compound $\mathbf{6 b}$ showed maximum inhibitory activity with $\mathrm{IC}_{50}=7.0$ and 16.3, respectively. Perusal of the literature revealed that anticancer activities of chromone based compounds have been identified with various molecular mechanisms including carcinogen inactivation, antiproliferation, cell cycle arrest, induction of apoptosis and differentiation, inhibition of angiogenesis, antioxidant, and reversal of multidrug resistance [27]. Flavopiridol, derived from rohitukine, which is an alkaloidal-flavonoid present in the Indian plant Dysoxylum binectariferum, induces cell-cycle arrest at both G1 and G2 phases and is a potent inhibitor of CDK1, 2, 4 , and 6 in a competitive manner with respect to ATP [28]. Quercetin, the natural flavonoid is reported to arrest the cell cycle and proliferation in prostate cancer cells by modulation of CDK1/Cyclin B; cell cycle analysis showed that it blocks G2-M transition with a significant induction of apoptosis [29]. Psorospermin is a chromone-based molecule possessing an epoxide group and has been reported to display a significant cytotoxic activity with topoisomerase II inhibitory potential. It is proposed that psorospermin's xanthone group intercalates with DNA and the epoxide ring undergoes alkylation at the $\mathrm{N}_{7}$-guanine base of DNA in the presence of topoisomerase II [30-32].
Though systemic establishment of the structure activity relationship has not been taken up, however, based on the presently observed cytotoxic activity of chromenopyridones against various human cancer cell lines, it emerges that compound bearing allyl moiety such as $\mathbf{6 b}$ showed better cytotoxic activity than simple chromenopyridones. Compounds bearing electron withdrawing groups such as chloro and bromo at $\mathrm{C}_{6}, \mathrm{C}_{7}$, and $\mathrm{C}_{8}$ were found to be more active against cancer cells than compounds bearing an electron donating group.

\section{Conclusion}

The chromenopyridones $\mathbf{3} \mathbf{a}-\mathbf{j}$ and $\mathbf{6 a}-\mathbf{d}$ were synthesized and evaluated for their cytotoxic activity against various human cancer cell lines. All compounds were purified with column chromatography and characterized by spectroscopic $\left({ }^{1} \mathrm{H}\right.$ and ${ }^{13} \mathrm{C}$ NMR, IR, mass) and elemental analysis. The in vitro cytotoxic evaluation revealed that compounds bearing electron withdrawing groups on chromone moiety were more active against cancer cells than compounds bearing electron donating groups and allylated chromenopyridones (6a-d) displayed a higher activity. These "lead" compounds can be used for further anticancer drug development and their mode of action studies.

\section{Experimental}

4.1. Chemistry. Starting materials and reagents were purchased from commercial suppliers and used after further purification (crystallisation/distillation). JEOL AL-300FT (300 MHz) NMR spectrometer was used to record the ${ }^{1} \mathrm{H}$ NMR and ${ }^{13} \mathrm{C}$ NMR $(75 \mathrm{MHz})$. Chemical shift $(\delta)$ and coupling constant are reported in ppm and $\mathrm{Hz}$, respectively. Tetramethylsilane is used as the internal standard. IR spectra of compounds were recorded with shimadzu FT-IR $8400 \mathrm{~S}$ spectrophotometer by using $\mathrm{KBr}$ pellets and $\mathrm{CHCl}_{3}$ as solvent. Mass spectra were recorded on Shimadzu GCMS-QP2000A (EI method) and Bruker Daltonics Esquire 3000 (ESIMS method) spectrometers.

4.2. Synthesis of Substituted 1-Phenyl-5-oxo-chromano[2,3-b]dihydro-2[1H]-pyridones $(\mathbf{3} \mathbf{a}-\mathbf{j})$. To solutions of substituted 2-anilino-3-formylchromone $(\mathbf{1 a}-\mathbf{j}, 0.53 \mathrm{~g}, 2.0 \mathrm{mmol})$ in dry benzene $(100 \mathrm{~mL})$, ethoxycarbonylmethylene-triphenylphosphorane $(0.7 \mathrm{~g}, 2.0 \mathrm{mmol})$ was added and the reaction mixtures were refluxed with stirring till the completion of reaction ( $12 \mathrm{~h}, \mathrm{TLC})$. The solvent was removed under vacuum so as to reduce the volume to about $10 \mathrm{~mL}$ and the solutions were kept under refrigeration until cream colored crystal separated. The crystals were filtered out and recrystallized from benzene to obtain the titled compounds as off-white solids [24].

4.3. Synthesis of Substituted 3-Allyl-1-phenyl-5-oxo-chromano [2,3-b]dihydro-2[1H]-pyridones (6a-d). 2-(N-Allyl-anilino)-3-(E- $\beta$-ethoxycarbonyl-ethenyl)-chromones (5a-d, $1.00 \mathrm{mmol})$ were dissolved in xylene $(10 \mathrm{~mL})$ and sealed in 
TABLE 2: $\mathrm{IC}_{50}(\mu \mathrm{M})$ of synthesized compounds against various human cancer cell lines.

\begin{tabular}{|c|c|c|c|c|c|}
\hline \multirow[b]{2}{*}{ Compound number } & \multicolumn{5}{|c|}{$\mathrm{IC}_{50} \pm \mathrm{SE}^{*}$ in $\mu \mathrm{M}$} \\
\hline & $\begin{array}{c}\text { PC-3 } \\
\text { (Prostate) }\end{array}$ & $\begin{array}{l}\text { MCF-7 } \\
\text { (Breast) } \\
\end{array}$ & $\begin{array}{c}\text { IMR-32 } \\
\text { (CNS) }\end{array}$ & $\begin{array}{c}\text { Hela } \\
\text { (Cervix) }\end{array}$ & $\begin{array}{c}\text { Hep-G2 } \\
\text { (Liver) }\end{array}$ \\
\hline $3 a$ & $82.4 \pm 3.5$ & $90.6 \pm 2.5$ & $80.4 \pm 3.5$ & $>100$ & $>100$ \\
\hline $3 b$ & $79.2 \pm 3.5$ & $80.2 \pm 3$ & $>100$ & $>100$ & $90.6 \pm 2.5$ \\
\hline $3 c$ & $88.9 \pm 2.3$ & $>100$ & $90.4 \pm 3.5$ & $88.8 \pm 1.3$ & $>100$ \\
\hline $3 d$ & $78.2 \pm 2.4$ & $86.2 \pm 3.5$ & $77.4 \pm 3.5$ & $>100$ & $83.5 \pm 1.2$ \\
\hline $3 e$ & $81.9 \pm 2.6$ & $83.2 \pm 1.5$ & $93.2 \pm 2.5$ & $>100$ & $>100$ \\
\hline $3 f$ & $28.7 \pm 3.3$ & $39.6 \pm 3.5$ & $23.9 \pm 2.8$ & $15.7 \pm 3.5$ & $>100$ \\
\hline $3 g$ & $21.5 \pm 2.5$ & $23.8 \pm 3.2$ & $19.2 \pm 2.3$ & $20.4 \pm 1.5$ & $44.1 \pm 2.1$ \\
\hline $3 h$ & $41.9 \pm 3.5$ & $15.5 \pm 2.3$ & $>100$ & $28.7 \pm 1.5$ & $85.6 \pm 2.2$ \\
\hline $3 \mathbf{i}$ & $80.3 \pm 1.3$ & $54.6 \pm 3.8$ & $33.7 \pm 1.2$ & $21.8 \pm 3.5$ & $54.2 \pm 2.6$ \\
\hline $3 \mathbf{j}$ & $54.2 \pm 2.5$ & $33.4 \pm 1.2$ & $19.2 \pm 2.5$ & $88.2 \pm 3.2$ & $38.9 \pm 1.1$ \\
\hline $6 a$ & $19.5 \pm 2.4$ & $>100$ & $33.5 \pm 3.3$ & $36.1 \pm 2.1$ & $44.9 \pm 3.2$ \\
\hline $6 b$ & $2.4 \pm 3.4$ & $10.7 \pm 2.5$ & $13.2 \pm 2.3$ & $7.0 \pm 3.5$ & $16.3 \pm 3.5$ \\
\hline $6 c$ & $13.4 \pm 1.1$ & $11.0 \pm 2.3$ & $15.6 \pm 2.1$ & $41.9 \pm 3.5$ & $23.6 \pm 2.5$ \\
\hline $6 \mathrm{~d}$ & $14.1 \pm 2.2$ & $14.6 \pm 1.5$ & $16.3 \pm 1.4$ & $>100$ & $41.0 \pm 2.3$ \\
\hline Paclitaxel & - & $0.2 \pm 0.03$ & - & - & - \\
\hline 5-Fluorouracil & - & - & $1.3 \pm 0.01$ & - & $0.5 \pm 0.05$ \\
\hline Mitomycin-C & $1.5 \pm 0.02$ & - & - & $2.0 \pm 0.03$ & - \\
\hline
\end{tabular}

Standard error $( \pm)$.

the glass tubes, which were heated at $220-230^{\circ} \mathrm{C}(6 \mathrm{~h})$. The tubes were chilled and cut and solvents were evaporated under reduced pressure to $1 / 4$ of the original volume. The crystal which appeared after being kept for two hours under refrigeration was filtered and recrystallized from benzene to obtain the substituted 3-allyl-1-phenyl-5-oxo-chromano $[2,3-b]$ dihydro-2 $[1 H]$-pyridones $(\mathbf{6 a}-\mathbf{d})$ as brown crystalline solids [24].

Spectral data of synthesized compounds $\mathbf{3} \mathbf{a}-\mathbf{j}$ and $\mathbf{6 a}-\mathbf{d}$.

4.3.1. 1-Phenyl-5-oxo-chromano[2,3-b]-dihydro-2[1H]-pyridone (3a). Off-white solid, mp: $284-285^{\circ} \mathrm{C}$; $\mathrm{IR}\left(\mathrm{CHCl}_{3}\right)$ $\nu_{\max }: 1678,1663,1647,1630,1600,1560,1517,1481,1458$, 1404, 1353, 1281, $1224 \mathrm{~cm}^{-1} ;{ }^{1} \mathrm{H}$ NMR $\left(\mathrm{CDCl}_{3}, 300 \mathrm{MHz}\right): \delta$ 8.20-8.14 (overlapping doublets, $2 \mathrm{H}, J=9 \mathrm{~Hz}, \mathrm{C}_{4} \& \mathrm{C}_{6}-\mathrm{Hs}$ ), 7.60-7.20 (m, 7H, arom-Hs), $7.1\left(\mathrm{~d}, 1 \mathrm{H}, J=9 \mathrm{~Hz}, \mathrm{C}_{9}-\mathrm{H}\right)$, $6.50\left(\mathrm{~d}, 1 \mathrm{H}, J=9.9 \mathrm{~Hz}, \mathrm{C}_{3}-\mathrm{H}\right) ;{ }^{13} \mathrm{C} \mathrm{NMR}\left(\mathrm{CDCl}_{3}, 75 \mathrm{MHz}\right)$ : $\delta 173.3\left(\mathrm{C}_{5}\right), 161.6\left(\mathrm{C}_{2}\right), 156.1\left(\mathrm{C}_{10 \mathrm{a}}\right), 153.6\left(\mathrm{C}_{9 \mathrm{a}}\right), 136.1$ $(\mathrm{CH}), 133.9(\mathrm{CH}), 132.5(\mathrm{~N}-\mathrm{Ph}), 129.6(\mathrm{CH}), 129.2(\mathrm{CH})$, 128.4 (CH), $126.7(\mathrm{CH}), 125.9(\mathrm{CH}), 122.2\left(\mathrm{C}_{5 \mathrm{a}}\right), 117.5\left(\mathrm{C}_{9}\right)$, $117.0(\mathrm{CH}), 102.3\left(\mathrm{C}_{4 \mathrm{a}}\right)$; Mass $m / z: 290\left(\mathrm{M}^{+}+1\right), 289\left(\mathrm{M}^{+}\right)$;

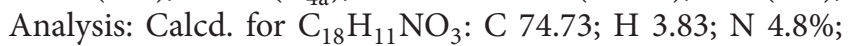
Found: C 74.65; H 3.76; N 4.73\%.

4.3.2. 7,9-Dichloro-1-phenyl-5-oxo-chromano[2,3-b]-dihydro2[1H]-pyridone (3b). Off-white solid, mp: $286-287^{\circ} \mathrm{C}$; $\operatorname{IR}\left(\mathrm{CHCl}_{3}\right) \nu_{\max }: 1693,1687,1654,1622,1596,1575,1562$, 1540, 1458, 1419, 1394, 1319, $1213 \mathrm{~cm}^{-1} ;{ }^{1} \mathrm{H}$ NMR $\left(\mathrm{CDCl}_{3}\right.$, $300 \mathrm{MHz}): \delta 8.20\left(\mathrm{~d}, 1 \mathrm{H}, J=10.7 \mathrm{~Hz}, \mathrm{C}_{4}-\mathrm{H}\right), 8.10(\mathrm{~d}, 1 \mathrm{H}, J=$ $\left.2.4 \mathrm{~Hz}, \mathrm{C}_{8}-\mathrm{H}\right), 7.62-7.21(\mathrm{~m}, 5 \mathrm{H}$, arom-Hs), $6.61(\mathrm{~d}, 1 \mathrm{H}$,
$\left.J=10.0 \mathrm{~Hz}, \mathrm{C}_{3}-\mathrm{H}\right) ;{ }^{13} \mathrm{C} \mathrm{NMR}\left(\mathrm{CDCl}_{3}, 75 \mathrm{MHz}\right): \delta 175.3$ $\left(\mathrm{C}_{5}\right), 164.6\left(\mathrm{C}_{2}\right), 157.2\left(\mathrm{C}_{10 \mathrm{a}}\right), 155.3\left(\mathrm{C}_{9}\right), 154.2\left(\mathrm{C}_{7}\right), 153.6$ $\left(\mathrm{C}_{9 \mathrm{a}}\right), 138.5(\mathrm{CH}), 137.9(\mathrm{CH}), 136.5(\mathrm{~N}-\mathrm{Ph}), 132.6(\mathrm{CH})$, $132.1(\mathrm{CH}), 131.4(\mathrm{CH}), 128.7(\mathrm{CH}), 126.9(\mathrm{CH}), 124.2$ $\left(\mathrm{C}_{5 \mathrm{a}}\right), 105.3\left(\mathrm{C}_{4 \mathrm{a}}\right)$; Mass $m / z$ : $358\left(\mathrm{M}^{+}\right)$; Analysis: Calcd. for $\mathrm{C}_{18} \mathrm{H}_{11} \mathrm{Cl}_{2} \mathrm{NO}_{3}$ : C 60.36; H 2.53; N 3.91\%; Found: C 60.45; $\mathrm{H} 2.47$; N 3.84\%.

4.3.3. 7-Flouro-1-phenyl-5-oxo-chromano[2,3-b]-dihydro2[1H]-pyridone (3c). Off-white solid,mp: $281-282^{\circ} \mathrm{C}$; IR $\left(\mathrm{CHCl}_{3}\right) v_{\text {max }}: 1685,1657,1642,1627,1608,1554,1522$, $1475,1456,1415,1345,1274,1230 \mathrm{~cm}^{-1} ;{ }^{1} \mathrm{H} \mathrm{NMR}\left(\mathrm{CDCl}_{3}\right.$, $300 \mathrm{MHz}): \delta 7.92\left(\mathrm{~s}, 1 \mathrm{H}, \mathrm{C}_{6}-\mathrm{H}\right), 7.71(\mathrm{~d}, 1 \mathrm{H}, J=9.2 \mathrm{~Hz}$, $\left.\mathrm{C}_{4}-\mathrm{H}\right), 7.62-6.90(\mathrm{~m}, 7 \mathrm{H}$, arom-Hs), $6.64(\mathrm{~d}, 1 \mathrm{H}, J=9.6 \mathrm{~Hz}$, $\left.\mathrm{C}_{3}-\mathrm{H}\right) ;{ }^{13} \mathrm{C} \mathrm{NMR}\left(\mathrm{CDCl}_{3}, 75 \mathrm{MHz}\right): \delta 172.1\left(\mathrm{C}_{5}\right), 161.4$ $\left(\mathrm{C}_{2}\right), 155.9\left(\mathrm{C}_{10 \mathrm{a}}\right), 151.8\left(\mathrm{C}_{9 \mathrm{a}}\right), 134.0(\mathrm{q}), 133.8(\mathrm{CH}), 133.5$ $(\mathrm{N}-\mathrm{Ph}), 133.9(\mathrm{CH}), 131.6(\mathrm{CH}), 129.5(\mathrm{CH}), 128.3(\mathrm{CH})$, $125.9(\mathrm{CH}), 123.2\left(\mathrm{C}_{5 \mathrm{a}}\right), 119.1\left(\mathrm{C}_{9}\right), 117.3(\mathrm{CH}), 102.0\left(\mathrm{C}_{4 \mathrm{a}}\right)$; Mass $m / z: 347\left(\mathrm{M}^{+}+\mathrm{K}\right)$; Analysis: Calcd. for $\mathrm{C}_{18} \mathrm{H}_{10} \mathrm{FNO}_{3}$ : C 70.36; H 3.28; N 4.56\%; Found: C 70.42; H 3.26; N 4.63\%.

4.3.4. 7-Methyl-1-phenyl-5-oxo-chromano[2,3-b]-dihydro2[1H]-pyridone (3d). Off-white solid, mp: $287-288^{\circ} \mathrm{C}$; IR $\left(\mathrm{CHCl}_{3}\right) v_{\text {max }}: 1679,1658,1637,1622,1589,1562,1540$, $1458,1436,1394,1340,1320,1294 \mathrm{~cm}^{-1} ;{ }^{1} \mathrm{H}$ NMR $\left(\mathrm{CDCl}_{3}\right.$, $300 \mathrm{MHz}): \delta 8.0\left(\mathrm{~s}, 1 \mathrm{H}, \mathrm{C}_{6}-\mathrm{H}\right), 8.24\left(\mathrm{~d}, 1 \mathrm{H}, J=9.3 \mathrm{~Hz}, \mathrm{C}_{4}-\mathrm{H}\right)$, 7.64-6.91 (m, 7H, arom-Hs), $6.53\left(\mathrm{~d}, 1 \mathrm{H}, J=9.3 \mathrm{~Hz}, \mathrm{C}_{3}-\mathrm{H}\right)$, 2.41 (s, $\left.\mathrm{CH}_{3}-\mathrm{Hs}\right) ;{ }^{13} \mathrm{C} \mathrm{NMR}\left(\mathrm{CDCl}_{3}, 75 \mathrm{MHz}\right): \delta 170.3\left(\mathrm{C}_{5}\right)$, $160.6\left(\mathrm{C}_{2}\right), 155.1\left(\mathrm{C}_{10 \mathrm{a}}\right), 152.6\left(\mathrm{C}_{9 \mathrm{a}}\right), 136.8(\mathrm{CH}), 136.2\left(\mathrm{C}_{7}\right)$, $135.6(\mathrm{CH}), 130.5(\mathrm{~N}-\mathrm{Ph}), 129.0(\mathrm{CH}), 129.2(\mathrm{CH}), 126.8$ 
$(\mathrm{CH}), 126.71(\mathrm{CH}), 120.2\left(\mathrm{C}_{5 \mathrm{a}}\right), 117.9\left(\mathrm{C}_{9}\right), 117.09(\mathrm{CH})$, $117.5\left(\mathrm{C}_{4 \mathrm{a}}\right), 21.5\left(\mathrm{CH}_{3}\right)$; Mass $m / z: 304\left(\mathrm{M}^{+}+1\right)$; Analysis: Calcd. for $\mathrm{C}_{19} \mathrm{H}_{13} \mathrm{NO}_{3}$ : C 75.24; $\mathrm{H} 4.32 ; \mathrm{N} 4.62 \%$; Found: $\mathrm{C}$ 75.30; $\mathrm{H} 4.35$; $\mathrm{N} 4.58 \%$.

4.3.5. 8-Chloro-7-flouro-1-phenyl-5-oxo-chromano[2,3-b]dihydro-2[1H]-pyridone (3e). Cream coloured solid, mp: $286-287^{\circ} \mathrm{C}$; IR $\left(\mathrm{CHCl}_{3}\right) \nu_{\max }: 1697,1676,1649,1580,1540$, $1510,1496,1446,1396,1342,1260,1215,1116 \mathrm{~cm}^{-1} ;{ }^{1} \mathrm{H}$ $\operatorname{NMR}\left(\mathrm{CDCl}_{3}, 300 \mathrm{MHz}\right): \delta 8.28\left(\mathrm{~d}, 1 \mathrm{H}, J=8.7 \mathrm{~Hz}, \mathrm{C}_{4}-\mathrm{H}\right)$, 7.65-7.10 (m, 7H, arom-Hs), $6.67\left(\mathrm{~d}, 1 \mathrm{H}, J=9.6 \mathrm{~Hz}, \mathrm{C}_{3}-\mathrm{H}\right)$; ${ }^{13} \mathrm{C} \mathrm{NMR}\left(\mathrm{CDCl}_{3}, 75 \mathrm{MHz}\right): \delta 174.2\left(\mathrm{C}_{5}\right), 163.6\left(\mathrm{C}_{2}\right), 156.2$ $\left(\mathrm{C}_{10 \mathrm{a}}\right), 154.1\left(\mathrm{C}_{9}\right), 153.1\left(\mathrm{C}_{7}\right), 152.6\left(\mathrm{C}_{9 \mathrm{a}}\right), 137.5(\mathrm{CH}), 137.1$ $(\mathrm{CH}), 136.2(\mathrm{~N}-\mathrm{Ph}), 131.6(\mathrm{CH}), 131.1(\mathrm{CH}), 130.4(\mathrm{CH})$, $128.3(\mathrm{CH}), 126.2(\mathrm{CH}), 123.1\left(\mathrm{C}_{5 \mathrm{a}}\right), 103.2\left(\mathrm{C}_{4 \mathrm{a}}\right)$; Mass $m / z$ : $341.5\left(\mathrm{M}^{+}+\mathrm{Na}\right)$; Analysis: Calcd. for $\mathrm{C}_{18} \mathrm{H}_{9} \mathrm{ClFNO}_{3}: \mathrm{C}$ 63.27; H 2.65; N 4.10\%; Found: C 63.21; H 2.61; N 4.14\%.

4.3.6. 8-Flouro-1-phenyl-5-oxo-chromano[2,3-b]-dihydro$2[1 \mathrm{H}]$-pyridone (3f). Off-white solid, mp: $283-284^{\circ} \mathrm{C}$; $\operatorname{IR}\left(\mathrm{CHCl}_{3}\right) v_{\text {max }}: 1685,1654,1625,1537,1488,1438,1400$, $1369,1321,1260,1232,1182,1114 \mathrm{~cm}^{-1} ;{ }^{1} \mathrm{H} \mathrm{NMR}\left(\mathrm{CDCl}_{3}\right.$, $300 \mathrm{MHz}$ ): $\delta 8.21$ (overlapping doublets, $2 \mathrm{H}, J=9.6 \mathrm{~Hz}, \mathrm{C}_{4} \&$ $\left.\mathrm{C}_{6}-\mathrm{Hs}\right), 7.72-7.15(\mathrm{~m}, 7 \mathrm{H}$, arom-Hs), $6.65(\mathrm{~d}, 1 \mathrm{H}, J=9.3 \mathrm{~Hz}$, $\left.\mathrm{C}_{3}-\mathrm{H}\right) ;{ }^{13} \mathrm{C} \mathrm{NMR}\left(\mathrm{CDCl}_{3}, 75 \mathrm{MHz}\right): \delta 171.0\left(\mathrm{C}_{5}\right), 160.3\left(\mathrm{C}_{2}\right)$, $155.2\left(\mathrm{C}_{10 \mathrm{a}}\right), 153.7\left(\mathrm{C}_{9 \mathrm{a}}\right), 135.3$ (q-arom.), $132.9(\mathrm{CH}), 132.1$ $(\mathrm{N}-\mathrm{Ph}), 131.0(\mathrm{CH}), 130.7(\mathrm{CH}), 129.6(\mathrm{CH}), 127.2(\mathrm{CH})$, $126.0(\mathrm{CH}), 121.2\left(\mathrm{C}_{5 \mathrm{a}}\right), 118.1\left(\mathrm{C}_{9}\right), 117.3(\mathrm{CH}), 101.4\left(\mathrm{C}_{4 \mathrm{a}}\right)$; Mass $m / z$ : $347\left(\mathrm{M}^{+}+\mathrm{K}\right)$; Analysis: Calcd. for $\mathrm{C}_{18} \mathrm{H}_{10} \mathrm{FNO}_{3}$ : C 70.36; H 3.28; N 4.56\%; Found: C 70.31; H 3.19; N 4.47\%.

4.3.7. 7-Chloro-1-phenyl-5-oxo-chromano[2,3-b]-dihydro2[1H]-pyridone (3g). Off-white solid, mp: $285-286^{\circ} \mathrm{C}$; IR $\left(\mathrm{CHCl}_{3}\right) v_{\max }: 1691,1649,1622,1581,1556,1540,1506$, 1487, 1452, 1434, 1393, 1318, $1191 \mathrm{~cm}^{-1} ;{ }^{1} \mathrm{H}$ NMR $\left(\mathrm{CDCl}_{3}\right.$, $300 \mathrm{MHz}): \delta 8.23\left(\mathrm{~d}, 1 \mathrm{H}, J=8.4 \mathrm{~Hz}, \mathrm{C}_{4}-\mathrm{H}\right), 7.63-7.06(\mathrm{~m}, 8 \mathrm{H}$, arom-Hs), $6.66\left(\mathrm{~d}, 1 \mathrm{H}, J=9.3 \mathrm{~Hz}, \mathrm{C}_{3}-\mathrm{H}\right) .{ }^{13} \mathrm{C} \mathrm{NMR}\left(\mathrm{CDCl}_{3}\right.$, $75 \mathrm{MHz}): \delta 172.0\left(\mathrm{C}_{5}\right), 161.3\left(\mathrm{C}_{2}\right), 156.0\left(\mathrm{C}_{10 \mathrm{a}}\right), 151.7\left(\mathrm{C}_{9 \mathrm{a}}\right)$, $135.7(\mathrm{q}), 133.9(\mathrm{CH}), 133.4(\mathrm{~N}-\mathrm{Ph}), 132.0(\mathrm{CH}), 131.7(\mathrm{CH})$, $129.6(\mathrm{CH}), 128.2(\mathrm{CH}), 126.0(\mathrm{CH}), 123.2\left(\mathrm{C}_{5 \mathrm{a}}\right), 119.1$ $\left(\mathrm{C}_{9}\right), 117.3(\mathrm{CH}), 101.9\left(\mathrm{C}_{4 \mathrm{a}}\right)$; Mass $m / z: 349\left(\mathrm{M}^{+}+\mathrm{Na}+2\right)$; Analysis: Calcd. for $\mathrm{C}_{18} \mathrm{H}_{10} \mathrm{ClNO}_{3}$ : C 66.78; H 3.11; N 4.33\%; Found: C 66.71; H 3.15; N 4.37\%.

4.3.8. 8-Chloro-1-phenyl-5-oxo-chromano[2,3-b]-dihydro2[1H]-pyridone (3h). Off-white solid,mp: $286-287^{\circ} \mathrm{C}$; IR $\left(\mathrm{CHCl}_{3}\right) v_{\max }: 1689,1654,1639,1626,1607,1508,1520$, $1485,1464,1409,1353,1279,1229 \mathrm{~cm}^{-1} ;{ }^{1} \mathrm{H} \mathrm{NMR}\left(\mathrm{CDCl}_{3}\right.$, $300 \mathrm{MHz}$ ): $\delta 8.24$ (overlapping doublets, $2 \mathrm{H}, J=9.4 \mathrm{~Hz}, \mathrm{C}_{4} \&$ $\mathrm{C}_{6}$-Hs), 7.81-6.95 (m, 7H, arom-Hs), $5.82(\mathrm{~d}, 1 \mathrm{H}, J=9.5 \mathrm{~Hz}$, $\left.\mathrm{C}_{3}-\mathrm{H}\right) ;{ }^{13} \mathrm{C} \mathrm{NMR}\left(\mathrm{CDCl}_{3}, 75 \mathrm{MHz}\right): \delta 172.0\left(\mathrm{C}_{5}\right), 161.1$ $\left(\mathrm{C}_{2}\right), 156.8\left(\mathrm{C}_{10 \mathrm{a}}\right), 150.9\left(\mathrm{C}_{9 \mathrm{a}}\right), 135.2(\mathrm{q}), 133.5(\mathrm{CH}), 133.1$ $(\mathrm{N}-\mathrm{Ph}), 132.1(\mathrm{CH}), 131.8(\mathrm{CH}), 129.2(\mathrm{CH}), 128.1(\mathrm{CH})$, $126.9(\mathrm{CH}), 123.1\left(\mathrm{C}_{5 \mathrm{a}}\right), 118.1\left(\mathrm{C}_{9}\right), 117.1(\mathrm{CH}), 101.4\left(\mathrm{C}_{4 \mathrm{a}}\right)$; Mass $m / z$ : $363\left(\mathrm{M}^{+}+\mathrm{K}\right)$; Analysis: Calcd. for $\mathrm{C}_{18} \mathrm{H}_{10} \mathrm{ClNO}_{3}$ : C 66.78; H 3.11; N 4.33\%; Found: C 66.63; H 3.12; N 4.35\%.
4.3.9. 9-Chloro-1-phenyl-5-oxo-chromano[2,3-b]-dihydro2[1H]-pyridone (3i). Off-white solid, mp: $284-285^{\circ} \mathrm{C}$; IR $\left(\mathrm{CHCl}_{3}\right) v_{\max }: 1693,1649,1627,1610,1579,1540,1495$, 1469, 1446, 1396, 1346, 1290, $1265 \mathrm{~cm}^{-1} ;{ }^{1} \mathrm{H}$ NMR $\left(\mathrm{CDCl}_{3}\right.$, $300 \mathrm{MHz}$ ): $\delta 8.21$ (overlapping doublets, $2 \mathrm{H}, J=9.6 \mathrm{~Hz}, \mathrm{C}_{4} \&$ $\left.\mathrm{C}_{6}-\mathrm{Hs}\right), 7.83-7.08$ (m, 7H, arom-Hs), $6.54(\mathrm{~d}, 1 \mathrm{H}, J=9.3 \mathrm{~Hz}$, $\left.\mathrm{C}_{3}-\mathrm{H}\right) ;{ }^{13} \mathrm{C} \mathrm{NMR}\left(\mathrm{CDCl}_{3}, 75 \mathrm{MHz}\right): \delta 171.6\left(\mathrm{C}_{5}\right), 162.0$ $\left(\mathrm{C}_{2}\right), 157.9\left(\mathrm{C}_{10 \mathrm{a}}\right), 150.5\left(\mathrm{C}_{9 \mathrm{a}}\right), 135.1(\mathrm{q}), 133.2(\mathrm{CH}), 133.0$ $(\mathrm{N}-\mathrm{Ph}), 131.0(\mathrm{CH}), 130.1(\mathrm{CH}), 129.1(\mathrm{CH}), 128.8(\mathrm{CH})$, $126.2\left(\mathrm{C}_{9}\right), 122.1\left(\mathrm{C}_{5 \mathrm{a}}\right), 117.1(\mathrm{CH}), 101.1\left(\mathrm{C}_{4 \mathrm{a}}\right)$; Mass $m / z$ : $322\left(\mathrm{M}^{+}+1\right)$; Analysis: Calcd. for $\mathrm{C}_{18} \mathrm{H}_{10} \mathrm{ClNO}_{3}$ : C 66.78; $\mathrm{H}$ 3.11; N 4.33\%; Found: C 66.59; H 3.05; N 4.29\%.

4.3.10. 7-Bromo-1-phenyl-5-oxo-chromano[2,3-b]-dihydro2[1H]-pyridone (3j). Off-white solid, mp: $288-289^{\circ} \mathrm{C}$; IR $\left(\mathrm{CHCl}_{3}\right) v_{\text {max }}: 1685,1649,1620,1596,1573,1535,1492$, $1452,1396,1311,1255,1218,1186 \mathrm{~cm}^{-1} ;{ }^{1} \mathrm{H}$ NMR $\left(\mathrm{CDCl}_{3}\right.$, $300 \mathrm{MHz}): \delta 8.32\left(\mathrm{~s}, 1 \mathrm{H}, \mathrm{C}_{6}-\mathrm{H}\right), 8.10(\mathrm{~d}, 1 \mathrm{H}, J=9.9 \mathrm{~Hz}$, $\left.\mathrm{C}_{4}-\mathrm{H}\right), 7.52-7.05(\mathrm{~m}, 7 \mathrm{H}$, arom-Hs), $6.53(\mathrm{~d}, 1 \mathrm{H}, J=9.9$ $\left.\mathrm{Hz}, \mathrm{C}_{3}-\mathrm{H}\right) ;{ }^{13} \mathrm{C} \mathrm{NMR}\left(\mathrm{CDCl}_{3}, 75 \mathrm{MHz}\right): \delta 172.1\left(\mathrm{C}_{5}\right), 161.3$ $\left(\mathrm{C}_{2}\right), 156.0\left(\mathrm{C}_{10 \mathrm{a}}\right), 153.3\left(\mathrm{C}_{9 \mathrm{a}}\right), 135.7(\mathrm{CH}), 133.9(\mathrm{q}), 133.4$ $(\mathrm{N}-\mathrm{Ph}), 132.0(\mathrm{CH}), 131.7(\mathrm{CH}), 129.6(\mathrm{CH}), 128.3(\mathrm{CH})$, $126.0(\mathrm{CH}), 123.1\left(\mathrm{C}_{5 \mathrm{a}}\right), 119.1\left(\mathrm{C}_{9}\right), 117.3(\mathrm{CH}), 102.0\left(\mathrm{C}_{4 \mathrm{a}}\right)$; Mass $m / z$ : $368\left(\mathrm{M}^{+}\right)$; Analysis: Calcd. for $\mathrm{C}_{18} \mathrm{H}_{10} \mathrm{BrNO}_{3}: \mathrm{C}$ 58.72; H 2.74; N 3.80\%; Found: C 58.68; H 2.64; N 3.72\%.

4.3.11. 3-Allyl-1-phenyl-5-oxo-chromano[2,3-b]dihydro$2[1 \mathrm{H}]$-pyridone (6a). Brown crystalline solid, mp: $182-183^{\circ} \mathrm{C}$; IR $\left(\mathrm{CHCl}_{3}\right) v_{\max }: 1674,1649,1614,1583$, $1552,1481,1468,1450,1427,1410,1390,1344,1290,1267$, $1190 \mathrm{~cm}^{-1} ;{ }^{1} \mathrm{H} \mathrm{NMR}\left(\mathrm{CDCl}_{3}, 300 \mathrm{MHz}\right): \delta 8.24(\mathrm{dd}, 1 \mathrm{H}, J$ $\left.=8.1 \& 1.7 \mathrm{~Hz}, \mathrm{C}_{6}-\mathrm{H}\right), 8.02\left(\mathrm{~s}, 1 \mathrm{H}, \mathrm{C}_{4}-\mathrm{H}\right), 7.54-7.20(\mathrm{~m}$, $7 \mathrm{H}$, arom-Hs), $7.15\left(\mathrm{~d}, 1 \mathrm{H}, J=8.4 \mathrm{~Hz}, \mathrm{C}_{9}-\mathrm{H}\right), 6.05-5.92(\mathrm{~m}$, $\left.1 \mathrm{H}, \mathrm{C}_{2^{\prime}}-\mathrm{H}\right), 5.24\left(\mathrm{~d}, 1 \mathrm{H}, J=11.7 \mathrm{~Hz}, \mathrm{C}_{3^{\prime}}-\mathrm{H}\right), 5.11(\mathrm{~d}, 1 \mathrm{H}$, $\left.J=8.7 \mathrm{~Hz}, \mathrm{C}_{3^{\prime}}-\mathrm{H}\right), 3.33\left(\mathrm{dd}, 2 \mathrm{H}, J=5.7 \& 1.2 \mathrm{~Hz}, \mathrm{C}_{1^{\prime}}-\mathrm{H}\right)$; ${ }^{13} \mathrm{C} \mathrm{NMR}\left(\mathrm{CDCl}_{3}, 75 \mathrm{MHz}\right): \delta 173.6\left(\mathrm{C}_{5}\right), 161.6\left(\mathrm{C}_{2}\right), 154.7$ $\left(\mathrm{C}_{10 \mathrm{a}}\right), 153.4\left(\mathrm{C}_{9 \mathrm{a}}\right), 134.3(\mathrm{CH}), 134.0(\mathrm{~N}-\mathrm{Ph}), 133.7(\mathrm{CH})$, $132.0(\mathrm{CH}), 129.5(\mathrm{CH}), 129.4\left(\mathrm{C}_{3}\right), 128.3(\mathrm{CH}), 128.2(\mathrm{CH})$, $126.4(\mathrm{CH}), 125.6(\mathrm{CH}), 122.1\left(\mathrm{C}_{5 \mathrm{a}}\right), 117.7\left(\mathrm{C}_{9}\right), 117.4\left(\mathrm{C}_{3}\right)$, $101.9\left(\mathrm{C}_{4 \mathrm{a}}\right), 34.4\left(\mathrm{C}_{1}\right)$; Mass $m / z: 329\left(\mathrm{M}^{+}\right)$; Analysis: Calcd. for $\mathrm{C}_{21} \mathrm{H}_{15} \mathrm{NO}_{3}$ : C 76.58; $\mathrm{H} 4.59 ; \mathrm{N} 4.25 \%$; Found: $\mathrm{C} 76.51$; $\mathrm{H} 4.53$; N $4.21 \%$.

4.3.12. 3-Allyl-7-chloro-1-phenyl-5-oxo-chromano[2,3b]dihydro-2v[1H]-pyridone(6b). Brown crystalline solid, mp: $184-185^{\circ} \mathrm{C}$; IR $\left(\mathrm{CHCl}_{3}\right) v_{\max }: 1676,1643,1617,1580$, $1542,1496,1450,1430,1396,1350,1380,1225,1272$, $1219,1180 \mathrm{~cm}^{-1} ;{ }^{1} \mathrm{H}$ NMR $\left(\mathrm{CDCl}_{3}, 300 \mathrm{MHz}\right): \delta 8.12(\mathrm{~d}$, $\left.1 \mathrm{H}, J=2.1 \mathrm{~Hz}, \mathrm{C}_{6}-\mathrm{H}\right), 8.02\left(\mathrm{~s}, 1 \mathrm{H}, \mathrm{C}_{4}-\mathrm{H}\right), 7.55-6.94(\mathrm{~m}$, 7H, arom-Hs), 6.01-5.93 (m, 1H, $\left.\mathrm{C}_{2}-\mathrm{H}\right), 5.22(\mathrm{~d}, 1 \mathrm{H}, J=$ $\left.11.4 \mathrm{~Hz}, \mathrm{C}_{3^{\prime}}-\mathrm{H}\right), 5.12\left(\mathrm{~d}, 1 \mathrm{H}, J=8.4 \mathrm{~Hz}, \mathrm{C}_{3^{\prime}}-\mathrm{H}\right), 3.31(\mathrm{~d}, 2 \mathrm{H}$, $\left.J=6.6 \mathrm{~Hz}, \mathrm{C}_{1}{ }^{\prime}-\mathrm{Hs}\right) ;{ }^{13} \mathrm{C} \mathrm{NMR}\left(\mathrm{CDCl}_{3}, 75 \mathrm{MHz}\right): \delta 173.2$ $\left(\mathrm{C}_{5}\right), 160.6\left(\mathrm{C}_{2}\right), 155.6\left(\mathrm{C}_{10 \mathrm{a}}\right), 154.2$ (q-arom.), $153.1\left(\mathrm{C}_{9 \mathrm{a}}\right)$, $134.9(\mathrm{CH}), 134.4(\mathrm{~N}-\mathrm{Ph}), 132.8(\mathrm{CH}), 128.9(\mathrm{CH}), 128.2$ $\left(\mathrm{C}_{3}\right), 127.6(\mathrm{CH}), 127.1(\mathrm{CH}), 126.1(\mathrm{CH}), 125.7(\mathrm{CH}), 120.1$ $\left(\mathrm{C}_{5 \mathrm{a}}\right), 117.9\left(\mathrm{C}_{9}\right), 117.3\left(\mathrm{C}_{3}\right), 101.2\left(\mathrm{C}_{4 \mathrm{a}}\right), 34.2\left(\mathrm{C}_{1}\right)$; Mass 
m/z: $363.5\left(\mathrm{M}^{+}\right)$; Analysis: Calcd. for $\mathrm{C}_{21} \mathrm{H}_{14} \mathrm{ClNO}_{3}$ : C 69.33; H 3.88; N 3.85\%; Found: C 69.27; H 3.78; N 3.82\%.

4.3.13. 3-Allyl-7-methyl-1-phenyl-5-oxo-chromano[2,3-b] dihydro-2[1H]-pyridone (6c). Brown crystalline solid, mp: $186-188^{\circ} \mathrm{C}$; IR $\left(\mathrm{CHCl}_{3}\right) v_{\max }: 1681,1652,1622,1578$, $1547,1505,1439,1427,1388,1356,1377,1228,1267,1227$, $1173 \mathrm{~cm}^{-1} ;{ }^{1} \mathrm{H}$ NMR $\left(\mathrm{CDCl}_{3}, 300 \mathrm{MHz}\right): \delta 8.01(\mathrm{~d}, 1 \mathrm{H}$, $\left.J=2.3 \mathrm{~Hz}, \mathrm{C}_{6}-\mathrm{H}\right), 7.72\left(\mathrm{~s}, 1 \mathrm{H}, \mathrm{C}_{4}-\mathrm{H}\right), 7.63-6.91(\mathrm{~m}, 7 \mathrm{H}$, arom-Hs), 6.03-5.92 (m, $\left.1 \mathrm{H}, \mathrm{C}_{2^{\prime}}-\mathrm{H}\right), 5.23(\mathrm{~d}, 1 \mathrm{H}, J=10.8 \mathrm{~Hz}$, $\left.\mathrm{C}_{3^{\prime}}-\mathrm{H}\right), 5.14\left(\mathrm{~d}, 1 \mathrm{H}, J=9.4 \mathrm{~Hz}, \mathrm{C}_{3^{\prime}}-\mathrm{H}\right), 3.3(\mathrm{~d}, 2 \mathrm{H}, J=6.4 \mathrm{~Hz}$, $\left.\mathrm{C}_{1^{\prime}}-\mathrm{Hs}\right), 2.3$ (s, 3H, $\left.\mathrm{CH}_{3}-\mathrm{Hs}\right) ;{ }^{13} \mathrm{C}$ NMR $\left(\mathrm{CDCl}_{3}, 75 \mathrm{MHz}\right)$ : $\delta 170.2\left(\mathrm{C}_{5}\right), 161.6\left(\mathrm{C}_{2}\right), 155.1\left(\mathrm{C}_{10 \mathrm{a}}\right), 152.1\left(\mathrm{C}_{9 \mathrm{a}}\right), 149.2$ (q-arom.), $134.4(\mathrm{~N}-\mathrm{Ph}), 132.8(\mathrm{CH}), 129.4(\mathrm{CH}), 128.2$ $(\mathrm{CH}), 127.9\left(\mathrm{C}_{3}\right), 127.1(\mathrm{CH}), 126.8(\mathrm{CH}), 126.0(\mathrm{CH}), 124.7$ $(\mathrm{CH}), 120.4\left(\mathrm{C}_{5 \mathrm{a}}\right), 117.5\left(\mathrm{C}_{9}\right), 117.1\left(\mathrm{C}_{3}\right), 100.2\left(\mathrm{C}_{4 \mathrm{a}}\right), 34.1$ $\left(\mathrm{C}_{1}\right)$, $22.5\left(\mathrm{CH}_{3}\right)$; HR-MS (ESI-TOF): $363.3400\left(\mathrm{M}^{+}+\mathrm{Na}\right)$; Analysis: Calcd. for $\mathrm{C}_{22} \mathrm{H}_{17} \mathrm{NO}_{3}$ : C 76.95; $\mathrm{H} \mathrm{4.99;} \mathrm{N} \mathrm{4.08 \% ;}$ Found: C 76.87; H 4.92; N 4.02\%.

4.3.14. 3-Allyl-7,9-dichloro-1-phenyl-5-oxo-chromano[2,3-b] dihydro-2[1H]-pyridone (6d). Brown crystalline solid, mp: $186-187^{\circ} \mathrm{C}$; IR $\left(\mathrm{CHCl}_{3}\right) v_{\max }: 1684,1649,1627,1582,1552$, $1511,1443,1434,1395,1363,1373,1222,1274,1221$, $1176 \mathrm{~cm}^{-1} ;{ }^{1} \mathrm{H}$ NMR $\left(\mathrm{CDCl}_{3}, 300 \mathrm{MHz}\right): \delta 8.1(\mathrm{~d}, 1 \mathrm{H}, J=$ $\left.2.4 \mathrm{~Hz}, \mathrm{C}_{6}-\mathrm{H}\right), 8.0\left(\mathrm{~s}, 1 \mathrm{H}, \mathrm{C}_{4}-\mathrm{H}\right), 7.5-6.9(\mathrm{~m}, 6 \mathrm{H}$, arom-Hs), 6.0-5.9 (m, 1H, $\left.\mathrm{C}_{2^{\prime}}-\mathrm{H}\right), 5.2\left(\mathrm{~d}, 1 \mathrm{H}, J=9.7 \mathrm{~Hz}, \mathrm{C}_{3^{\prime}}-\mathrm{H}\right), 5.2(\mathrm{~d}$, $\left.1 \mathrm{H}, J=10.3 \mathrm{~Hz}, \mathrm{C}_{3^{\prime}}-\mathrm{H}\right), 3.3\left(\mathrm{~d}, 2 \mathrm{H}, J=6.6 \mathrm{~Hz}, \mathrm{C}_{1^{\prime}}-\mathrm{Hs}\right) ;{ }^{13} \mathrm{C}$ NMR $\left(\mathrm{CDCl}_{3}, 75 \mathrm{MHz}\right): \delta 173.7\left(\mathrm{C}_{5}\right), 164.5\left(\mathrm{C}_{2}\right), 155.5(\mathrm{q}-$ arom.), $154.5\left(\mathrm{C}_{10 \mathrm{a}}\right), 153.1\left(\mathrm{C}_{9 \mathrm{a}}\right), 149.2(\mathrm{q}-\operatorname{arom}),. 134.7(\mathrm{~N}-$ $\mathrm{Ph}), 133.5(\mathrm{CH}), 130.8(\mathrm{CH}), 129.9(\mathrm{CH}), 128.1\left(\mathrm{C}_{3}\right), 127.5$ $(\mathrm{CH}), 126.1(\mathrm{CH}), 125.1(\mathrm{CH}), 122.7(\mathrm{CH}), 120.4\left(\mathrm{C}_{5 \mathrm{a}}\right), 117.9$ $\left(\mathrm{C}_{9}\right), 117.4\left(\mathrm{C}_{3}\right), 103.2\left(\mathrm{C}_{4 \mathrm{a}}\right), 34.5\left(\mathrm{C}_{1}\right)$; HR-MS (ESI-TOF): $420.030\left(\mathrm{M}^{+}+\mathrm{Na}-1\right)$; Analysis: Calcd. for $\mathrm{C}_{21} \mathrm{H}_{13} \mathrm{Cl}_{2} \mathrm{NO}_{3}: \mathrm{C}$ 63.34; H 3.29; N 3.52\%; Found: C 63.28; H 3.22; N 3.48\%.

4.4. Biological Activity. The sulforhodamine B (SRB) assay is a colorimetric assay used for cytotoxic screening to assess cell growth [26]. Cells are cultured in a 96-well tissue culture plates and the cell growth which depends upon the rate of multiplication is measured indirectly by the intensity of the color of the dye which is directly proportional to the number of cells present. The human cancer cell lines (procured from NCI, Frederick, USA) were grown in tissue culture flasks in complete growth medium (RPMI-1640 medium with $2 \mathrm{mM}$ glutamine, $\mathrm{pH} 7.4$, supplemented with $10 \%$ fetal calf serum, $100 \mu \mathrm{g} / \mathrm{mL}$ streptomycin, and 100 units $/ \mathrm{ml}$ penicillin) in a carbon dioxide incubator $\left(37^{\circ} \mathrm{C}, 5 \% \mathrm{CO}_{2}, 90 \% \mathrm{RH}\right)$. The cells at subconfluent stage were harvested from the flask by treatment with trypsin $(0.05 \%$ in PBS ( $\mathrm{pH} 7.4)$ containing $0.02 \%$ EDTA). Cells with viability of more than $98 \%$ as determined by trypan blue exclusion were used for the determination of cytotoxicity and the cell suspension of $1 \times$ $10^{5}$ cells/mL was prepared in a complete growth medium. Stock solutions $\left(2 \times 10^{-2} \mathrm{M}\right)$ of synthesized compounds $\mathbf{3 a}-\mathbf{j}$ and $\mathbf{6 a}-\mathbf{d}$ were prepared in DMSO. The stock solutions were serially diluted with a complete growth medium containing
$50 \mu \mathrm{g} / \mathrm{mL}$ of gentamycin to obtain working test solutions of required concentrations. In vitro cytotoxicity against four human cancer cell lines of different tissues was determined using 96-well tissue culture plates. The $100 \mu \mathrm{L}$ of cell suspension was added to each well of the 96-well tissue culture plate. The cells were allowed to grow in a carbon dioxide incubator $\left(37^{\circ} \mathrm{C}, 5 \% \mathrm{CO}_{2}, 90 \% \mathrm{RH}\right)$ for 24 hours. Test materials in complete growth medium $(100 \mu \mathrm{L})$ were added after 24 hours of incubation to the wells containing cell suspension. The plates were further incubated for 48 hours in a carbon dioxide incubator. The cell growth was stopped by gently layering trichloroacetic acid $(50 \%, 50 \mu \mathrm{L})$ on top of the medium in all the wells. The plates were incubated at $4^{\circ} \mathrm{C}$ for one hour to fix the cells attached to the bottom of the wells. The liquid of all the wells was gently pipetted out and discarded. The plates were washed five times with distilled water to remove trichloroacetic acid, growth medium low molecular weight metabolites, serum proteins, and so forth, and were airdried. The plates were stained with sulforhodamine $\mathrm{B}$ dye $(0.4 \%$ in $1 \%$ acetic acid, $100 \mu \mathrm{L})$ for 30 minutes. The plates were washed five times with $1 \%$ acetic acid and then airdried. The adsorbed dye was dissolved in Tris- $\mathrm{HCl}$ buffer $(100 \mu \mathrm{L}, 0.01 \mathrm{M}, \mathrm{pH} 10.4)$ and plates were gently stirred for 10 minutes on a mechanical stirrer. The optical density (OD) was recorded on ELISA reader at $540 \mathrm{~nm}$. The cell growth was determined by subtracting the mean OD value of respective blank from the mean OD value of experimental set. Percent growth in presence of the test material was calculated considering the growth in the absence of any test material as $100 \%$ and in turn percent growth inhibition in presence of the test material was calculated.

\section{References}

[1] S. Dadiboyena and A. Nefzi, "Synthesis of functionalized tetrasubstituted pyrazolyl heterocycles-a review," European Journal of Medicinal Chemistry, vol. 46, no. 11, pp. 5258-5275, 2011.

[2] W. Du, "Towards new anticancer drugs: a decade of advances in synthesis of camptothecins and related alkaloids," Tetrahedron, vol. 59, no. 44, pp. 8649-8687, 2003.

[3] G. Valdameri, E. G. Bastide, B. Peres et al., "Substituted chromones as highly potent nontoxic inhibitors, specific for the breast cancer resistance protein," Journal of Medicinal Chemistry, vol. 55, no. 2, pp. 966-970, 2012.

[4] A. Gaspar, T. Silva, M. Yáñez et al., "Chromone, a privileged scaffold for the development of monoamine oxidase inhibitors," Journal of Medicinal Chemistry, vol. 54, no. 14, pp. 5165-5173, 2011.

[5] F. A. Ramos, Y. Takaishi, M. Shirotori et al., "Antibacterial and antioxidant activities of quercetin oxidation products from yellow onion (Allium cepa) skin," Journal of Agricultural and Food Chemistry, vol. 54, no. 10, pp. 3551-3557, 2006.

[6] R. Goel, V. Sharma, A. Budhiraja, and M. P. S. Ishar, "Synthesis and evaluation of novel 3a, 9a-dihydro-1-ethoxycarbonyl-1cyclopenteno[5, 4-b]benzopyran-4-ones as antifungal agents," Bioorganic and Medicinal Chemistry Letters, vol. 22, no. 14, pp. 4665-4667, 2012.

[7] M. Kuroda, S. Uchida, K. Watanabe, and Y. Mimaki, "Chromones from the tubers of Eranthis cilicica and their 
antioxidant activity," Phytochemistry, vol. 70, no. 2, pp. 288-293, 2009.

[8] R. I. Brinkworth, M. J. Stoermer, and D. P. Fairlie, "Flavones are inhibitors of HIV-1 proteinase," Biochemical and Biophysical Research Communications, vol. 188, no. 2, pp. 631-637, 1992.

[9] I. W. Setnikar, M. J. Murmann, M. J. Magistrett, P. da Re, and L. Verlicchi, "N-substituted 8-aminomethylchromones, a new class of central nervous system stimulants," Journal of medicinal and pharmaceutical chemistry, vol. 3, pp. 471-488, 1961.

[10] S. A. Galal, A. S. Abd El-All, M. M. Abdallah, and H. I. ElDiwani, "Synthesis of potent antitumor and antiviral benzofuran derivatives," Bioorganic and Medicinal Chemistry Letters, vol. 19, no. 9, pp. 2420-2428, 2009.

[11] K. Serge, G. T. Hubert, B. Janine, B. Pierre, and M. Marie, "Synthesis and evaluate the anti-allergic and antihistamine activity of benzyl-3-chromones (homo-isoflavones)," European Journal of Medicinal Chemistry, vol. 24, no. 5, pp. 541-546, 1989.

[12] T. H. Tseng, S. K. Chuang, C. C. Hu et al., "The synthesis of morusin as a potent antitumor agent," Tetrahedron, vol. 66, no. 6, pp. 1335-1340, 2010.

[13] T. Raj, R. K. Bhatia, A. kapur, M. Sharma, A. K. Saxena, and M. P. S. Ishar, "Cytotoxic activity of 3-(5-phenyl$3 \mathrm{H}-[1,2,4]$ dithiazol-3-yl)chromen-4-ones and 4-oxo-4Hchromene-3-carbothioic acid N-phenylamides," European Journal of Medicinal Chemistry, vol. 45, no. 2, pp. 790-794, 2010.

[14] M. P. S. Ishar, G. Singh, S. Singh, K. K. Sreenivasan, and G. Singh, "Design, synthesis, and evaluation of novel 6chloro-/fluorochromone derivatives as potential topoisomerase inhibitor anticancer agents," Bioorganic and Medicinal Chemistry Letters, vol. 16, no. 5, pp. 1366-1370, 2006.

[15] Q. Li, A. Claiborne, T. Li et al., "Design, synthesis, and activity of 4-quinolone and pyridone compounds as nonthiol-containing farnesyltransferase inhibitors," Bioorganic and Medicinal Chemistry Letters, vol. 14, no. 21, pp. 5367-5370, 2004.

[16] H. M. Hassanin and S. M. El-edfawy, "Novel heterocyclic derivatives of 2-quinolinone associated with antibacterial and antitumor potencies," Hetreocycles, vol. 85, no. 10, pp. 2421-2436, 2012.

[17] D. D. Erol and N. Yulug, "Synthesis and antimicrobial investigation of thiazolinoalkyl-4(1H)-pyridones," European Journal of Medicinal Chemistry, vol. 29, no. 11, pp. 893-897, 1994.

[18] A. G. E. Amr and M. M. Abdulla, "Anti-inflammatory profile of some synthesized heterocyclic pyridone and pyridine derivatives fused with steroidal structure," Bioorganic and Medicinal Chemistry, vol. 14, no. 13, pp. 4341-4352, 2006.

[19] X. Fan, D. Feng, Y. Qu et al., "Practical and efficient synthesis of pyrano[3,2-c]pyridone, pyrano[4,3-b]pyran and their hybrids with nucleoside as potential antiviral and antileishmanial agents," Bioorganic and Medicinal Chemistry Letters, vol. 20, no. 3, pp. 809-813, 2010.

[20] M. E. Wall, M. C. Wani, C. E. Cook, K. H. Palmer, A. T. McPhail, and G. A. Sim, "Plant antitumor agents VI: the isolation and structure of taxol, a novel antilekemic and antitumor agent from Taxus brevifolia," Journal of American Chemical Society, vol. 88, no. 16, pp. 3888-3892, 1966.

[21] W. D. Kingsbury, J. C. Boehm, D. R. Jakas et al., "Synthesis of water-soluble (aminoalkyl)camptothecin analogues: inhibition of topoisomerase I and antitumor activity," Journal of Medicinal Chemistry, vol. 34, no. 1, pp. 98-107, 1991.
[22] M. S. Butler, "Natural products to drugs: natural productderived compounds in clinical trials," Natural Product Reports, vol. 25, no. 3, pp. 475-516, 2008.

[23] G. Singh, R. Singh, N. K. Girdhar, and M. P. S. Ishar, "A versatile route to 2-alkyl-/aryl-amino-3-formyl- and hetero-annelatedchromones, through a facile nucleophilic substitution at $\mathrm{C} 2$ in 2-(N-methylanilino)-3-formylchromones," Tetrahedron, vol. 58, no. 12, pp. 2471-2480, 2002.

[24] G. Singh, G. Singh, and M. P. S. Ishar, "Pericyclic transformations at the periphery of chromen-4-one (4H-1-benzopyran-4one): an unusual preference for a 1,5-shift of allylic moieties over the ene reaction," Helvetica Chimica Acta, vol. 86, no. 1, pp. 169-180, 2003.

[25] D. Mou, W. Zhao, T. Zhang et al., "Two new chromanone derivatives from the roots and stems of Nicotiana tabacum and their cytotoxicity," Heterocycles, vol. 85, no. 10, pp. 2485-2490, 2012.

[26] P. Skehan, R. Storeng, D. Scudiero et al., "New colorimetric cytotoxicity assay for anticancer-drug screening," Journal of the National Cancer Institute, vol. 82, no. 13, pp. 1107-1112, 1990.

[27] W. Ren, Z. Qiao, H. Wang, L. Zhu, and L. Zhang, "Flavonoids: promising anticancer agents," Medicinal Research Reviews, vol. 23, no. 4, pp. 519-534, 2003.

[28] A. M. Senderowicz, "The cell cycle as a target for cancer therapy: basic and clinical findings with the small molecule inhibitors flavopiridol and UCN-01," Oncologist, vol. 7, supplement 3, pp. 12-19, 2002.

[29] M. R. Vijayababu, P. Kanagaraj, A. Arunkumar, R. Ilangovan, M. M. Aruldhas, and J. Arunakaran, "Quercetin-induced growth inhibition and cell death in prostatic carcinoma cells (PC-3) are associated with increase in p21 and hypophosphorylated retinoblastoma proteins expression," Journal of Cancer Research and Clinical Oncology, vol. 131, no. 11, pp. 765-771, 2005.

[30] S. M. Kupchan, D. R. Streelman, and A. T. Sneden, "Psorospermin, a new antileukemic xanthone from psorospermum febrifugum," Journal of Natural Products, vol. 43, no. 2, pp. 296-301, 1980.

[31] J. M. Cassady, W. M. Baird, and C. J. Chang, "Natural products as a source of potential cancer chemotherapeutic and chemopreventive agents," Journal of Natural Products, vol. 53, no. 1, pp. 23-41, 1990.

[32] M. Hansen, S. J. Lee, J. M. Cassady, and L. H. Hurley, "Molecular details of the structure of a psorospermin-DNA covalent/intercalation complex and associated DNA sequence selectivity," Journal of the American Chemical Society, vol. 118, no. 24, pp. 5553-5561, 1996. 

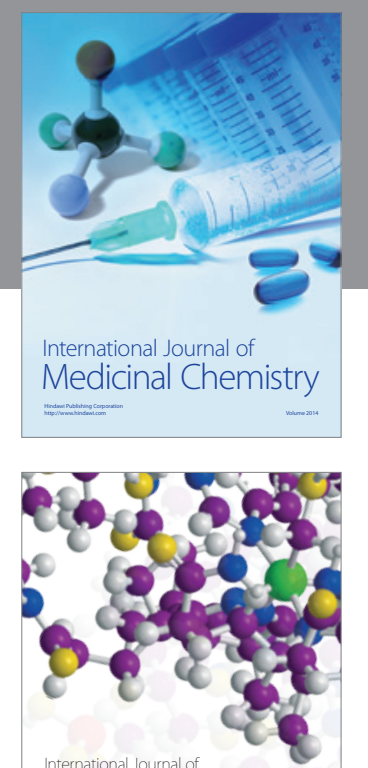

\section{Carbohydrate} Chemistry

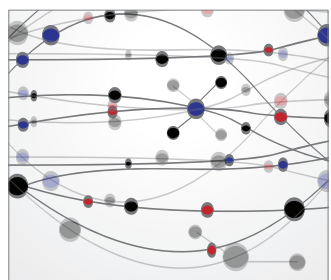

The Scientific World Journal
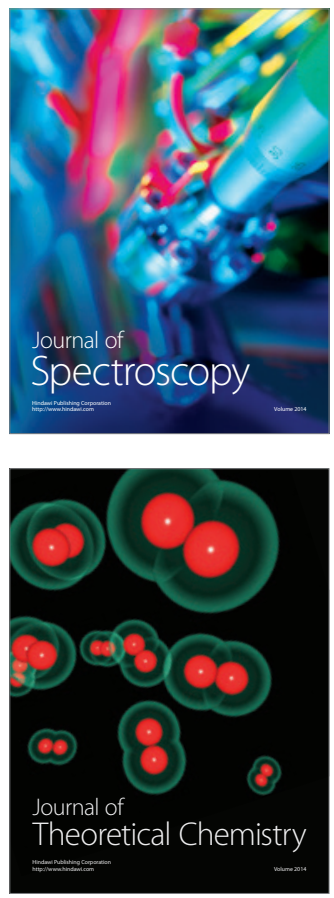
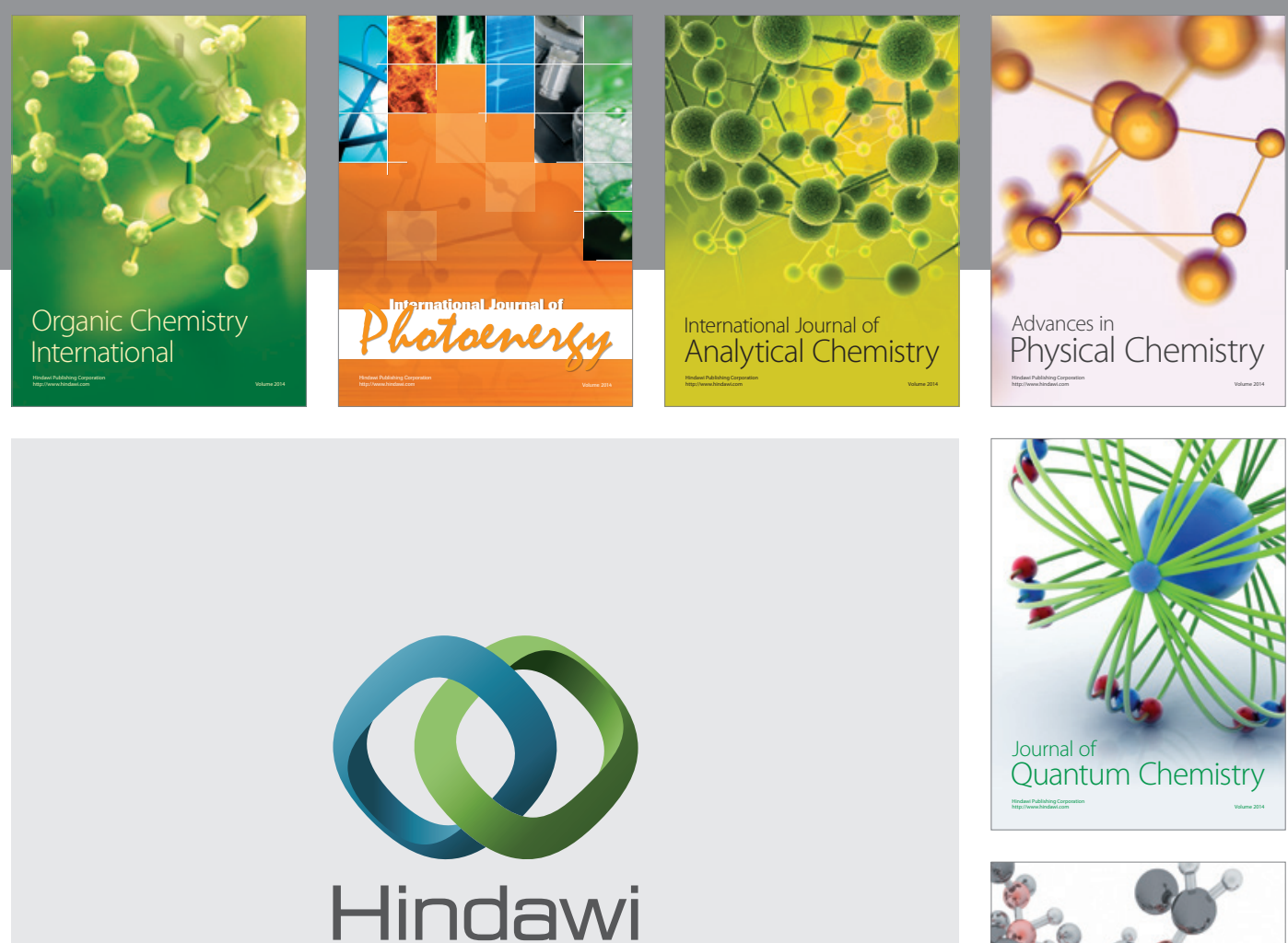

Submit your manuscripts at

http://www.hindawi.com

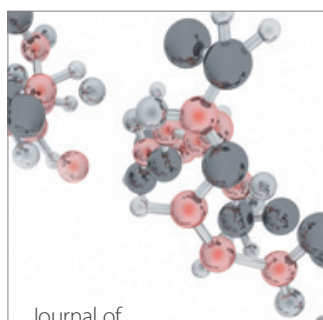

Analytical Methods

in Chemistry

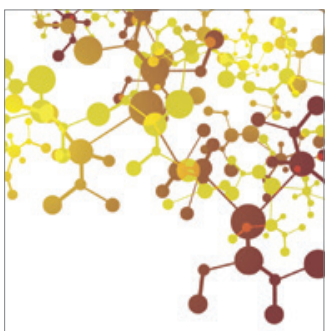

Journal of

Applied Chemistry

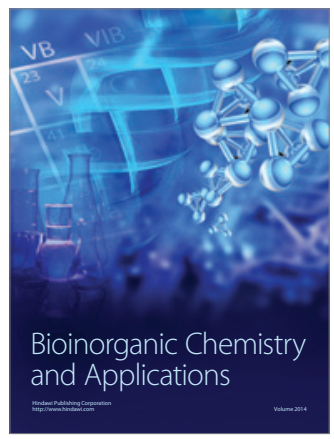

Inorganic Chemistry
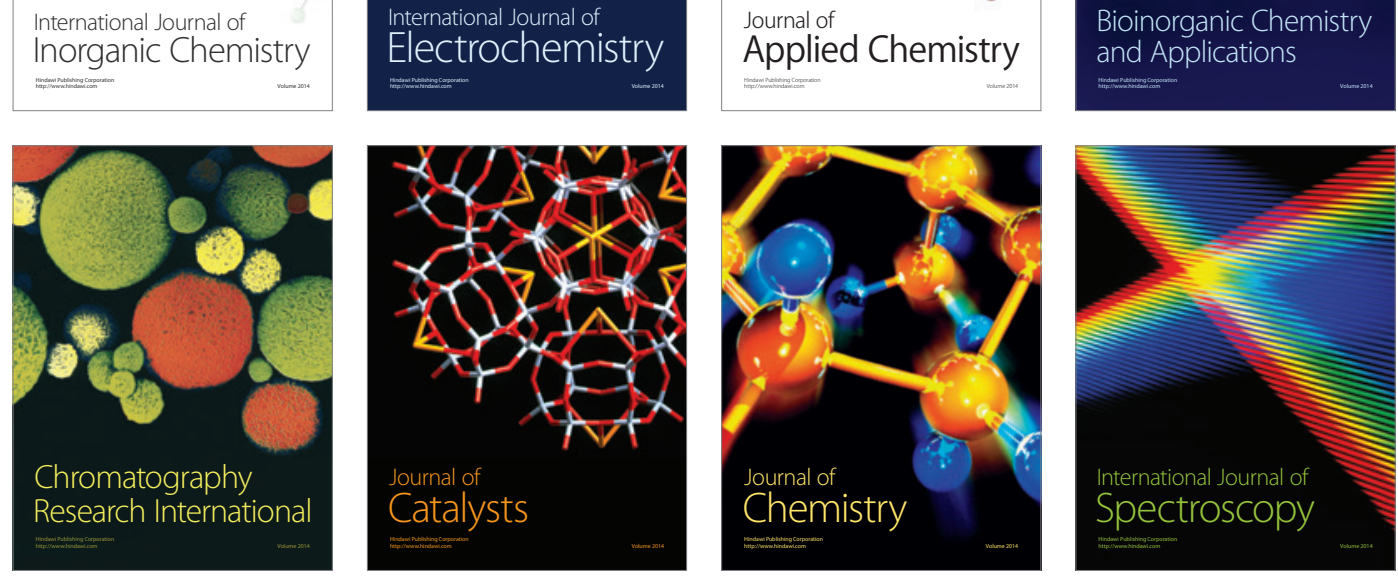